\title{
Fabrication and characterization of high-strength PVDF/nonwoven fabric electrospun composite membranes for direct contact membrane distillation
}

\author{
Kuiling Lia ${ }^{\mathrm{a}, \mathrm{b}}$, Jiang Chang ${ }^{\mathrm{c}}$, Deyin Hou ${ }^{\mathrm{a}, \mathrm{b}, *}$, Chunli Ding ${ }^{\mathrm{d}}$, Jun Wang ${ }^{\mathrm{b}}$ \\ ${ }^{a}$ Key Laboratory of Drinking Water Science and Technology, Research Center for Eco-Environmental Sciences, \\ Chinese Academy of Sciences, Beijing 100085, PR China, Tel. +86 10 62917207; Fax: +86 10 62917207; \\ email: dyhou@rcees.ac.cn (D. Hou) \\ ${ }^{b}$ State Key Laboratory of Environmental Aquatic Chemistry, Research Center for Eco-Environmental Sciences, \\ Chinese Academy of Sciences, Beijing 100085, PR China \\ 'Laboratory of Environmental Technology, Institute of Nuclear and New Energy Technology, Tsinghua University, Beijing 100084, PR China \\ ${ }^{d}$ School of Chemical Engineering and Technology, Hebei University of Technology, Tianjin 300130, PR China
}

Received 9 April 2017; Accepted 27 September 2017

\begin{abstract}
A B S T R A C T
The polyvinylidene fluoride (PVDF) nanofibers composite membranes were fabricated for membrane distillation using polyester nonwoven fabric as a substrate via electrospinning. The influences of nonwoven fabric and electrospinning time on membrane morphology, hydrophobicity, pore size and pore size distribution, porosity, mechanical strength and permeability were evaluated. All the electrospun composite membranes had a three-dimensional bead-fiber interconnected open structure and a rough membrane surface with water contact angle of greater than $140^{\circ}$. The composite membranes obtained high-mechanical strength because of nonwoven fabric substrate, which was important for industrial application. The resultant membranes were tested through direct contact membrane distillation (DCMD) using $3.5 \mathrm{wt} \%$ sodium chloride solution as feed, and the highest permeate flux was up to $54.0 \mathrm{~kg} / \mathrm{m}^{2} \mathrm{~h}$ at feed temperature of $80^{\circ} \mathrm{C}$. The anti-fouling properties of the fabricated membrane were investigated by DCMD experiment with mixed solution including sodium chloride, calcium chloride and humic acid, and the composite membrane presented excellent anti-fouling performance. During sodium chloride solution concentration process, it was demonstrated that the permeability and hydrophobicity of the composite membrane can maintain well after repeated use and rinse. The results suggested the potential of the electrospun PVDF/nonwoven fabric composite membrane for membrane distillation application.
\end{abstract}

Keywords: Membrane distillation; Hydrophobic surface; Electrospinning; Polyvinylidene fluoride; Nonwoven fabric; Mechanical strength

\footnotetext{
* Corresponding author.
} 